\title{
A Comparative Study of Malaysian and Japanese Actinomycetes Using a Simple Identification Method Based on Partial 16S rDNA Sequence
}

\author{
Hideyuki Muramatsu ${ }^{1 *}$, Neelam Shahab ${ }^{2}$, Yasuhisa Tsurumi ${ }^{1}$ and Motohiro Hino ${ }^{1}$ \\ ${ }^{1}$ Exploratory Research Laboratories, Fujisawa Pharmaceutical Co. Ltd., 5-2-3, Tokodai, Tsukuba, Ibaraki, 300-2698, Japan \\ ${ }^{2}$ Environment \& Bioprocess Technology Centre, SIRIM Berhad, 1, Persiaran Dato’ Menteri, Section 2, P.O. Box 7035, 40911 \\ Shah Alam, Selangor, Malaysia
}

(Received Oct. 3, 2003 / Accepted Nov. 6, 2003)

\begin{abstract}
A comparative analysis was performed on the taxonomy of actinomycete isolates of Malaysia and Japan. The taxonomical positions of isolates were determined using a simple identification method based on $16 \mathrm{~S}$ rDNA partial sequence homology. The $16 \mathrm{~S}$ rDNA partial sequence determination was made by direct PCR and direct sequencing. Simple identification was attempted for each of the $\mathbf{1 1 2 8}$ actinomycete isolates for each country. We succeeded in simple identification of 790 Malaysian and 981 Japanese isolates. Malaysian isolates belonged to 9 families, 23 genera, and 185 species, including one genus as yet undescribed. The Japanese isolates belonged to 9 families, 22 genera, and 207 species. There was little taxonomical overlap between Malaysian isolates and Japanese isolates. Only 14\% of the species and only 50\% of the genera occurred in both groups. These results indicate that a group of actinomycetes of greater taxonomic diversity can be obtained when gathered from both regions, rather than from one or the other. Among Malaysian isolates, two strains were found that apparently do not belong to any known genus. Phylogenetic analysis indicates that they belong to the suborder Sreptosporangineae. The existence of candidate strains of a novel genus suggests that Malaysian actinomycetes have not been thoroughly investigated and therefore has promising potential as a source for novel bioactive compounds.
\end{abstract}

\section{INTRODUCTION}

Actinomycetes are well-known as a good source of natural product-based drug discovery programs. However, in recent times, the rate of discovery of novel bioactive compounds originating from actinomycetes has slowed ${ }^{1)}$. Nevertheless, we believe that expanding the diversity of isolates will lead to renewed discovery.

Tropical rainforests are generally regarded as treasuries of biodiversity. The diversity of the tropical flora has been reported to be many times greater than that of the temperate flora $\left.{ }^{2}, 3\right)$. However, few reports have addressed the diversity of tropical actinomycetes ${ }^{4-6)}$. Wang et al. reported on actinomycete diversity in the tropical rainforests of Singapore, finding 36 genera after identifying 5,000 isolates $^{4}$. Moreover, they discovered representatives of apparently novel genera ${ }^{4}{ }^{7)}$. However, no report to date has examined numerous isolates to determine possible differences in diversity between actinomycetes in the Temperate Zone and that in the Tropical Zone.

To date, for handling of numerous strains, bacterial taxonomic position has primarily been determined by morphological observation, sometimes augmented by chemotaxonomical method ${ }^{4-6}$. However, these methods have weaknesses in both accuracy and objectivity. For bacterial taxonomy, phylogenetic analysis by $16 \mathrm{~S}$ rDNA sequences has become the standard approach. However, for the treatment of many isolates, DNA sequence analysis is costly in terms of money, time and effort. Recently, Tsuchizaki et al. have reported that colony direct PCR may also be applied to actinomycetes ${ }^{8}$. Independently, we have devised direct PCR method using a culture broth. Combining this direct PCR method and the direct sequencing method, we devised a 16S rDNA partial sequence-based simple identification system that enabled simple identification of thousands of isolates.

This is the first reported analysis comparing actinomycetes gathered from a tropical rainforest and that from the Temperate Zone, using isolates numbering on the order of thousands, and based on a simple identification system involving partial $16 \mathrm{~S}$ rDNA sequencing.

\section{MATERILAS AND METHODS}

\section{Soil Samples}

Malaysian soil samples were collected at Bukit Lagong Forest Reserves, Rawang, Selangor. This area is located in the center of Peninsular Malaysia at $3^{\circ} 14^{\prime} \mathrm{N}$ and $101^{\circ} 38^{\prime}$

*Corresponding author. Phone: +29-847-8611. Fax: +29-847-8313. E-mail: hideyuki_muramatu@ po.fujisawa.co.jp 
E. Mean daily temperatures range from 27 to $32{ }^{\circ} \mathrm{C}$. Annual rainfall is between 2000 to $2900 \mathrm{~mm}^{9}$. Japanese soil samples were collected at Okutama, Tokyo, located on the Pacific side of central Honshu at $35^{\circ} 48^{\prime} \mathrm{N}$ and $139^{\circ} 3^{\prime}$ E. Mean daily temperatures range from 0.1 to $23.2^{\circ} \mathrm{C}$ (1979-2002). Annual rainfall is between 1092 to $2356 \mathrm{~mm}$ (1979-2000) (this data was collected at Ogouchi in the middle of Okutama) ${ }^{10}$. Soil samples of both areas were collected in natural forests or forested areas. Soil samples were stored at $8^{\circ} \mathrm{C}$ until actinomycete isolation. Actinomycete isolation was performed within two months of soil sampling.

\section{Actinomycetes isolation}

We employed three methods to expand the diversity of the actinomycete isolates:

1) Air-drying method: $0.2-0.5 \mathrm{~g}$ of soil was air-dried for one week at room temperature in tubes. Then $2 \mathrm{ml}$ of sterilized $0.01 \%$ polyoxyethylene sorbitan monooleate (Nacalai Tesque, Inc., Kyoto, Japan) was added to each tube and mixed vigorously. This suspension was sonicated in a bath-type sonicater for $5 \mathrm{~min}$. The suspension was diluted and spread onto isolation plates. This is a general isolation method for actinomycetes.

2) Centrifugation method: We employed modified Takeuchi's method ${ }^{11)}$. Air-dried soil $(0.2-0.5 \mathrm{~g})$ was gently mixed with $2 \mathrm{ml}$ of sterilized $0.01 \%$ polyoxyethylene sorbitan monooleate without using a mixer. After incubation at $30{ }^{\circ} \mathrm{C}$ for $1 \mathrm{hr}, 1 \mathrm{ml}$ of supernatant was transferred to a sterile sampling tube. Centrifugation was performed at 7,000 $\mathrm{rpm}(3,000 \times g)$, for $20 \mathrm{~min}$. The supernatant was then diluted and spread onto isolation plates. This method allows isolation of actinomycete strains having motile spores.

3) Chloramin $T$ method: We employed modified Hayakawa's method ${ }^{12)}$. Soil suspension was made by a procedure identical to air-drying method. $0.15 \mathrm{ml}$ of soil suspension was mixed with the same volume of $4 \%$ Chloramin $\mathrm{T}$ (dissolved in sterile water; Nacalai Tesque, Inc.) solution. After incubation at $30{ }^{\circ} \mathrm{C}$ for $30 \mathrm{~min}$, the suspension was diluted and spread onto isolation plates. The target taxon of this method is the family Streptosporangiaceae.
For isolation plates, we employed $\mathrm{HV}$ agar ${ }^{13)}$ plates with minor modification using "HUMAS" (Aiaisi kabusikigaisya, Osaka, Japan) as humic acid; $5 \mathrm{~g} / \mathrm{l}$. We also employed HV agar plates supplemented with antibiotic agents, streptomycin sulfate (5 mg/l; Sigma, St. Louis, U.S.A.) or novobiocin sodium salt (10 mg/l; Sigma) or erythromycin ( $2 \mathrm{mg} / \mathrm{l}$; Sigma).

The isolation plates were incubated at $30{ }^{\circ} \mathrm{C}$ for 14 to 30 days. Actinomycete colonies on isolation plates were transferred to 1/5 SY agar, while seeking to avoid the repeated selection of colonies of identical morphology from the same plate. 1/5 SY agar was prepared as follows: soluble starch; $2 \mathrm{~g} / 1$ (Nacalai Tesque, Inc.), yeast extract; $0.4 \mathrm{~g} / \mathrm{l}$ (Nacalai Tesque, Inc.), agar; $16 \mathrm{~g} / \mathrm{l}$ (after adjustment of $\mathrm{pH}$ to 7.3 with $1 \mathrm{~N} \mathrm{NaOH}$; Hayashi Pure Chemical Industries Ltd., Osaka, Japan), after autoclaving supplemented with cycloheximide (40 mg/l; Nacalai Tesque, Inc.).

\section{Isolates for simple identification}

2713 actinomycete strains were isolated from 85 Malaysian soil samples; 3690 actinomycete strains were isolated from 219 Japanese soil samples. For simple identification, 1128 isolates each from Japan and Malaysia were selected without morphological observation. To suppress any taxonomical skewing from isolation methods, the proportions of strains isolated by three isolation methods were kept nearly identical for the two regions. In selected strains, $36 \%$ of Malaysian and $34 \%$ of Japanese strains were isolated by the air-drying, general isolation method for actinomycetes. 13\% of Malaysian and 12\% of Japanese isolates were obtained by the centrifugation, zoospore selective method. 51\% of Malaysian and 54\% of Japanese isolates were obtained by the Chloramin $\mathrm{T}$, the family Streptosporangiaceae selective method (Table 1).

\section{Simple identification method}

Simple identification was carried out according to the following five steps:

1) Preparation of culture broth

Each isolate was incubated in a well of a 96-well format plate. $100 \mu \mathrm{l}$ of $1 / 2$ strength ISP-Medium 1 (Bacto Tryptone Yeast Extract Broth Dehydrated; Difco

Table 1. Isolates for simple identification.

\begin{tabular}{|c|c|c|c|c|c|c|c|c|c|c|c|c|}
\hline \multirow{2}{*}{\multicolumn{3}{|c|}{$\begin{array}{l}\text { Isolatioin Method } \\
\text { Isolation Medium }\end{array}$}} & \multicolumn{5}{|c|}{ Air Drying*1 } & \multicolumn{3}{|c|}{ Centrifugation $^{* 2}$} & \multirow{2}{*}{$\frac{\mathrm{CT}^{* 3}}{\mathrm{HV}(\%)}$} & \multirow{2}{*}{ Total } \\
\hline & & & $\mathrm{HV}$ & $\mathrm{SM}^{* 4}$ & $\mathrm{EM}^{* 5}$ & $\mathrm{NV}^{* 6}$ & $\operatorname{Total}(\%)$ & $\mathrm{HV}$ & $\mathrm{NV}^{* 6}$ & Total(\%) & & \\
\hline \multirow{2}{*}{\multicolumn{2}{|c|}{$\begin{array}{c}\text { Number of } \\
\text { Isolates }\end{array}$}} & Malaysia & 237 & 53 & 100 & 16 & 406(36) & 105 & 46 & 151(13) & $571(51)$ & $1128(100)$ \\
\hline & & Japan & 244 & 36 & 93 & 10 & $383(34)$ & 93 & 47 & $140(12)$ & $605(54)$ & $1128(100)$ \\
\hline \multicolumn{13}{|c|}{1 non-selective } \\
\hline \multicolumn{13}{|c|}{2 zoospore selective } \\
\hline \multicolumn{13}{|c|}{ Chloramin T: Streptosporangiaceae selective } \\
\hline \multicolumn{13}{|c|}{4 HV agar supplemented with Streptomycin (5 mg/l) } \\
\hline \multicolumn{13}{|c|}{ HV agar supplemented with Erythromycin $(2 \mathrm{mg} / \mathrm{l})$} \\
\hline \multicolumn{13}{|c|}{ HV agar supplemented with Novobiocin $(10 \mathrm{mg} / \mathrm{l})$} \\
\hline
\end{tabular}


Laboratories, Detroit, Michigan, U.S.A.) with $0.5 \%$ glycine (Kanto Chemical Co., Inc., Tokyo, Japan) and $0.01 \%$ polyoxyethylene sorbitan monooleate was dispensed to each well. A very small piece of the colony on 1/5 SY agar was inoculated in each well with a sterile toothpick. Incubation was performed at $30^{\circ} \mathrm{C}$ for about 16 hr without shaking. After incubation, plates were stored at $-80{ }^{\circ} \mathrm{C}$ until direct PCR amplification.

2) PCR amplification and sequencing

Nested PCR and direct PCR methods were employed. The PCR primers were designed to be actinomycete-specific in order to suppress the influence of contamination. The primers of the first PCR were SRR181F (5'- GTT TGA TCC TGG CTC AGG AC - 3') and SRR182R (5'GGT GTT CCT CMH GAT ATC TG - 3'), while those of the second PCR were SRR178F (5'- GAA CGC TGG CGG CGT GCT - 3') and SRR 179R (5' - GCG CAT TYC ACC GCT ACA CC - 3'). These primer sequences corresponded to nucleotide positions 10-29, 673-692, 30-47, and 654-673, respectively, according to the Streptomyces ambofaciens rDNA sequence ${ }^{14)}$. We employed KOD -Plus- (Toyobo Co., Ltd., Osaka, Japan) as a DNA polymerase for its high fidelity and thermostability. The first PCR reaction mixture was prepared as follows: forward and reverse primers, $0.825 \mathrm{pmol}$ each; dimethyl sulfoxide, $0.55 \mu \mathrm{l} ; 10 \times$ PCR buffer, $0.55 \mu 1$ (KOD -Plus-); deoxynucleoside triphosphates (dNTPs), $0.55 \mu \mathrm{l}(10 \mathrm{mM}$ each dNTP); KOD -Plus- DNA polymerase, $0.1 \mu \mathrm{l}$ ( 0.1 units); $\mathrm{H}_{2} \mathrm{O}$, to $5 \mu \mathrm{l}$. Culture broth $(0.5$ $\mu \mathrm{l})$ was added to the reaction mixture as a template. PCR was performed with Gene Amp PCR System 9700 (Applied Biosystems Japan Ltd., Tokyo, Japan). To extract genome DNA from the mycelia, to denature DNA, and to activate polymerase, pre-amplification steps of $10 \mathrm{sec}$ at 4 ${ }^{\circ} \mathrm{C}$ and $1 \mathrm{~min}$ at $99.9^{\circ} \mathrm{C}$ were performed. Amplification was performed using 10 cycles of $15 \mathrm{sec}$ of denaturing at $97{ }^{\circ} \mathrm{C}, 30 \mathrm{sec}$ at $55^{\circ} \mathrm{C}$ for primer annealing, and $2 \mathrm{sec}$ at 68 ${ }^{\circ} \mathrm{C}$ for primer extension, followed by cooling to $4{ }^{\circ} \mathrm{C}$. Following the first PCR reaction, the PCR reaction mixture was discarded and the second PCR performed using the same tube. The faint trace of the amplification product left in the tube then served as templates for the second PCR. The second PCR reaction mixture was prepared as follows: forward and reverse primers, 0.375 pmol each; dimethyl sulfoxide, $0.5 \mu 1 ; 10 \times$ PCR buffer, $0.5 \mu 1$; dNTPs, $0.5 \mu \mathrm{l}$; KOD -Plus- DNA polymerase, $0.1 \mu \mathrm{l}(0.1$ unit); $\mathrm{H}_{2} \mathrm{O}$, to $5 \mu \mathrm{l}$. After $1 \mathrm{~min}$ of denaturing at $99.9{ }^{\circ} \mathrm{C}$, amplification was performed by 40 cycles of $15 \mathrm{sec}$ of denaturing at $97{ }^{\circ} \mathrm{C}, 30 \mathrm{sec}$ at $64{ }^{\circ} \mathrm{C}$ for primer annealing, and extension, followed by cooling to $4{ }^{\circ} \mathrm{C}$. With no purification step, the second PCR product was used directly as a template for the sequencing reaction. Using the same tube as with second PCR, the product left in tube after discarding the reaction mixture in the preceding step was used as a template. Sequencing was performed using BigDye Terminator Cycle Sequencing Ready Reaction Kit
(Applied Biosystems Japan Ltd.) and ABI PRISM 3100 Genetic Analyzer (Applied Biosystems Japan Ltd.). To reduce cost, the premix was used at $1 / 4$ the strength recommended in the manufacture's instructions, reducing the reaction volume to $5 \mu \mathrm{l}$. The sequencing reaction mixture was prepared as follows: Terminator Ready Reaction Mix, $0.5 \mu \mathrm{l}$; Tris buffer $\left(200 \mathrm{mM}\right.$ Tris $\mathrm{HCl}, 5 \mathrm{mM} \mathrm{MgCl}{ }_{2}, \mathrm{pH}$ 8.0), $1.5 \mu \mathrm{l}$; SRR188F, 0.8 pmol; dimethyl sulfoxide, 0.25 $\mu \mathrm{l} ; \mathrm{H}_{2} \mathrm{O}$, to $5 \mu \mathrm{l}$. Ethanol precipitation was performed to purify the products, using a shredded glass fiber filter GA100 (Toyo Roshi Kaisha, Ltd., Tokyo, Japan) to absorb the supernatant.

3) Homology search and simple identification

The 16S rDNA sequence data for type strains of the order Actinomycetales, excluding the suborder Micrococcineae, was collected from DDBJ ${ }^{15)}$. The suborder Micrococcineae was excluded, since this study dealt with filamentous actinomycetes. There was relatively little sequence data available for the genus Streptomyces. As of October 2001, the number of approved species and subspecies in the genus Streptomyces was 474, whereas the number of available sequence data was 93 only (19.6\%, excluding short sequences and sequences including many "n"). On the other hand, in non-streptomyces, the number of approved species and subspecies was 555 and the number of available sequence data was 468 (84.3\%). To replenish the database sequence data, $16 \mathrm{~S}$ rDNA of 74 strains (Streptomyces; 73, Actinosynnema; 1 ) of type strain were sequenced and registered in the database (Table 2). The in-house database was created using Excel VBA (Microsoft Corporation) based on this data and homology searches were performed (unpublished data). To confirm the results, BLAST searches were performed on the DDBJ home site.

4) Genus determination

Genus determination must be made by the polyphasic analysis depending on chemotaxonomy and morphological characteristics, in addition to phylogenetic analysis by $16 \mathrm{~S}$ rDNA sequence. But in this study, for reasons of convenience, we employed a 16S rDNA homology value of $94 \%$ as a genus determination criterion. If an isolate demonstrated a 16S rDNA homology value with most homologous species exceeding this value, the isolate was simpleidentified as the genus of the species. The criterion was set at $94 \%$ because the intrageneric homology exceeded $94 \%$ in most genera ${ }^{16-24)}$. In other cases, we confirmed the genus of an isolate from its position on the phylogenic tree.

5) Species determination

Although the determination of bacterial species must be made by a hybridization test of genome DNA and the homology value of the 16S rDNA sequence does not become the determination criterion for species, there is close correlation between them. Keswani et al. showed that when the homology value of a pair of $16 \mathrm{~S}$ rDNA sequences is $98.6 \%$, there is a $99 \%$ probability that the 
value of DNA hybridization test will be less than $70 \%$, i.e., that they are from different species ${ }^{25}$. For reasons of convenience, we employed a $16 \mathrm{~S}$ rDNA homology value of $98.6 \%$ as a species determination criterion. If an isolate demonstrated a $16 \mathrm{~S}$ rDNA homology value exceeding this value, the isolate was simple-identified as the species. Otherwise, the isolate is considered to belong to a species the sequence for which has yet to be registered in the DDBJ or which has not been described. It should be noted that the number of species which was counted based on this criterion is a minimum estimate.

\section{Phylogenetic analysis}

Phylogenetic trees were constructed by the neighborjoining method ${ }^{26)}$ in the Clustal X package (version 1.8) ${ }^{27}$.

\section{RESULTS AND DISCUSSION}

\section{Simple identification}

We were able to simple-identify 790 Malaysian isolates and 981 Japanese isolates from 1128 strains from each respective region. The success rates for simple identification (number of simple-identified strains/number of strains tried to simple-identify) of Malaysian isolates and Japanese isolates were $70.0 \%$ and $87.0 \%$, respectively. Simple identification of these isolates was based on the result of a homology search of partial 16S rDNA sequences. The length of the sequences obtained from these isolates ranged from 402 to 589 nucleotides. Length exceeded 560 nucleotides in $85 \%$ of these sequences. In all, we attempted simple identification of no less than 2256 isolates, succeeding with $78.5 \%$. This rate is nearly equivalent to results obtained from simple identification by morphology ${ }^{4,28)}$. Among most isolates for which simple identification failed, the lack of success was attributable to PCR amplification failure. Improvement in PCR protocol would likely improve the success rate of simple identification. The rate for Malaysian isolates was lower than for Japanese isolates. We observed that Malaysian isolates tended to produce pigments in culture broth, pigments that may inhibit PCR amplification. This may help to explain the reasons for the lower success rate for PCR amplification of Malaysian isolates.

\section{Comparison of the frequencies of families}

About half of the species from both countries belonged to the family Streptomycetaceae (Malaysia; 49\%, Japan; $52 \%$ ). $19 \%, 17 \%$, and $6 \%$ of Malaysian species belonged to Micromonosporaceae, Streptosporangiaceae, and Nocardiaceae, respectively. $16 \%, 12 \%$, and $9 \%$ of Japanese species belonged to Streptosporangiaceae, Micromonosporaceae, and Nocardiaceae, respectively (Fig. 1). In all, the Malaysian and Japanese isolates represented 11 families. Seven families were found in both regions (Fig. 2). The families found only in Malaysia were Corynebacteriaceae (1 isolate) and Mycobacteriaceae (4 isolates, 2 species). The families found only in Japan were Geodermatophilaceae (1 isolate) and Actinosynnemataceae (1 isolate) (Table 3). Few isolates belonged to the families found only in one area or the other. The isolation frequen-

Table 2. Actinomycetes strains used in this study.

\begin{tabular}{|c|c|c|}
\hline Name & Strain No. & Accession No. \\
\hline $\begin{array}{l}\quad \text { (Type starins) } \\
\text { Streptomyces } 73 \text { strains } \\
\text { Actinosynnema } 1 \text { strain }\end{array}$ & 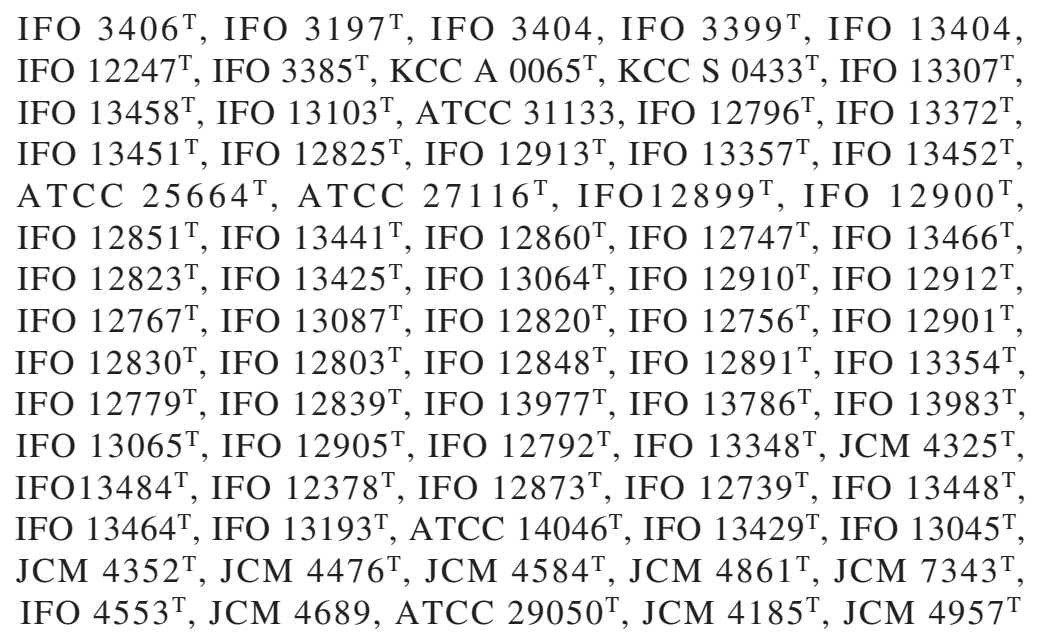 & $\begin{array}{l}\text { AB } 122707 \\
-\mathrm{AB} 122780\end{array}$ \\
\hline Malaysian soil isolates & $\begin{array}{l}\text { 384A03-384H12, 387A03-387H12, 410A03-410H12, 411А03-411H12, } \\
\text { 413A03-413H12, 415A03-415H12, 418A03-418H12, 419A03-419H12, } \\
\text { 424A03-424H12, 428A03-428H12, 431A03-431H12, 434A03-434H12 }\end{array}$ & $\begin{array}{l}\mathrm{AB} 122781 \\
-\mathrm{AB} 123570\end{array}$ \\
\hline Japanese soil isolates & 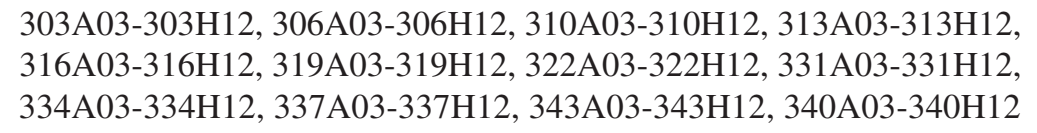 & $\begin{array}{l}\mathrm{AB} 123571 \\
\quad-\mathrm{AB} 124551\end{array}$ \\
\hline
\end{tabular}


cy of strains belonging to these taxa is considered to be low in both areas when isolating from soil using the methods in this study. The coincidence of the frequencies of the families of both areas reflects the same proportions of isolates obtained by each isolation method (Table 1).

\section{Comparison of the diversity of genera and species}

With two exceptions, the Malaysian isolates belonged to 22 known genera. We will discuss the taxonomic position of the two isolates later. The Japanese isolates belonged to 22 known genera. The species counts from Malaysian isolates and Japanese isolates were 185 and 207, respectively. The ratios of species counts to simple-identified isolates were 0.234 and 0.211 with Malaysian isolates and Japanese isolates, respectively. The ratio is considered to indicate species diversity, and there appears to be no significant difference between the ratio of Malaysian actinomycetes and that of Japanese actinomycetes. Given the lack of a clear-cut result from the comparison of actinomycete diversity based on approximately 1000 isolates from each region, we can hardly conclude that the diversity of Malaysian actinomycetes exceeds Japanese actinomycetes.

\section{Overlaps in genus and species level}

In all, the Malaysian and Japanese isolates represented 30 genera. Half of these were found in both Japan and Malaysia. The remaining half occurred only in one country or the other. At the species level, 185 species were counted from Malaysia and 207 species from Japan. Combined, the two countries accounted for 344 species; but only 48 species $(14 \%)$ were found in both areas (Fig. 2). Thus, the actinomycete species isolated from Japan and Malaysia show little overlap. These results are interpreted to indicate differences in species or genera frequency, not distribution.

The frequencies of the genera in each family, intrageneric phylogenetic analysis

In Japanese isolates, the predominant genus of the family Streptosporangiaceae was Sreptosporangium (57\%). In Malaysian isolates, the ratio of Streptosporangium was lower $(29 \%)$, while the ratio of Nonomuraea increased to $45 \%$ (Fig. 3). On the phylogenetic tree, Streptosporangium strains form two clades ${ }^{29)}$ (Fig. 4). Approximately about the same number of isolates from Malaysia and Japan was included in the clade, which contains $S$. viridialbum. The isolates of the other clade were almost all Japanese isolates. Streptosporangium was found in both countries, but it was suggested that Japanese and Malaysian isolates have partiality by the intrageneric distribution. Within the genus Nonomuraea, simple identification resulted in a count of up to 14 species from Malaysian isolates; these were widely distributed across the phylogenetic tree (Fig. 5). One Malaysian isolate (413B06) was simple-identified as Nonomuraea, due to $95 \%$ homology with Nonomuraea
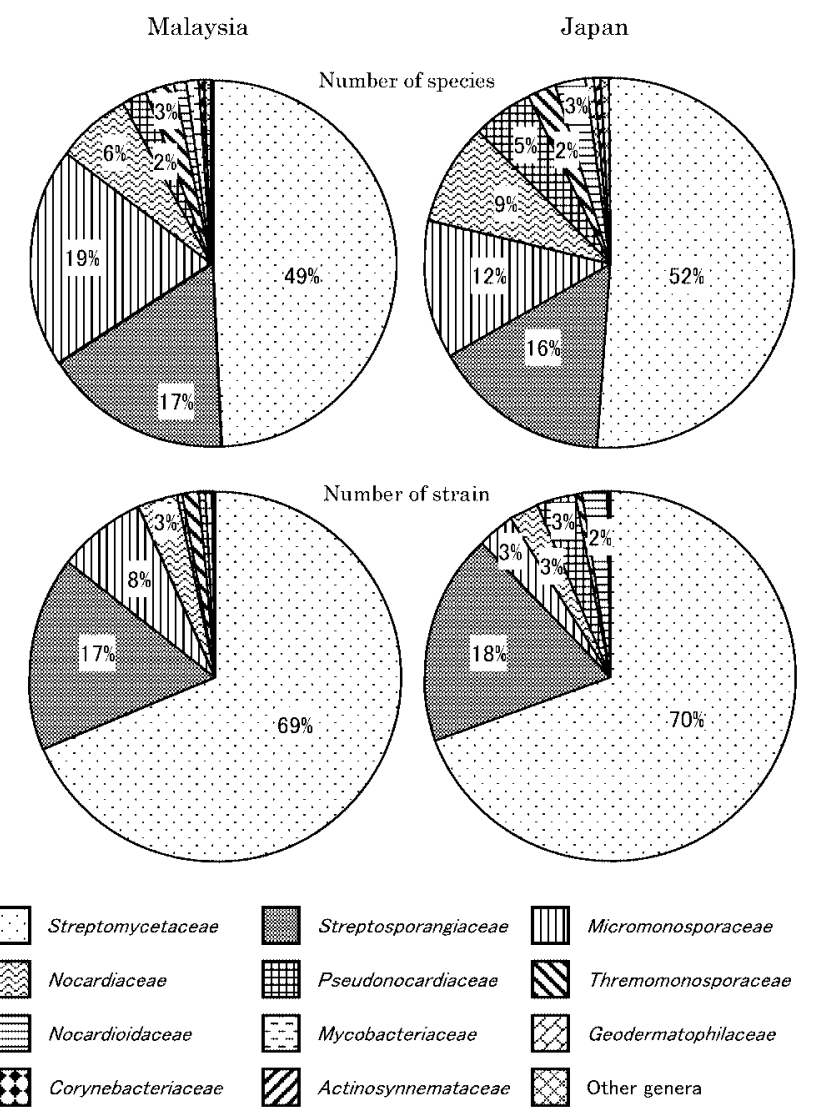

Fig. 1. Frequencies of families.

The percentages on the graphs are the frequencies of families (above $2 \%$ are indicated).

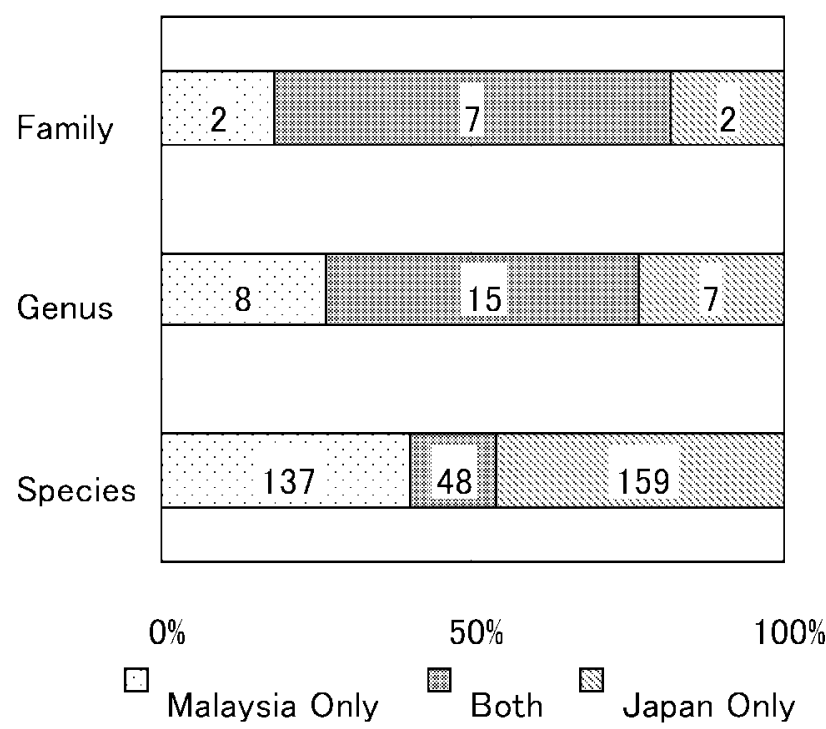

Fig. 2. Taxonomical overlaps between Malaysian isolates and Japanese isolates.

The numbers on the graphs are the numbers of taxa. 
Table 3. Actinomycetes found in Malaysia and Japan.

\begin{tabular}{|c|c|c|c|c|c|c|}
\hline \multirow[b]{2}{*}{ Family } & \multirow[b]{2}{*}{ Genus } & \multicolumn{2}{|c|}{ Number of isolates } & \multicolumn{3}{|c|}{ Number of species } \\
\hline & & Japan & Malaysia & $\begin{array}{c}\text { Japan } \\
\text { (Japan Only) }\end{array}$ & $\begin{array}{c}\text { Malaysia } \\
\text { (Malaysia Only) }\end{array}$ & Both \\
\hline Corynebacteriaceae & Corynebacterium & 0 & 1 & $0(0)$ & $1(1)$ & 0 \\
\hline Mycobacteriaceae & Mycobacterium & 0 & 4 & $0(0)$ & $2(2)$ & 0 \\
\hline \multirow[t]{2}{*}{ Nocardiaceae } & Nocardia & 24 & 23 & $17(12)$ & $10(5)$ & 5 \\
\hline & Rhodococcus & 1 & 2 & $1(1)$ & $2(2)$ & 0 \\
\hline Geodermatophilaceae & Blastococcus & 1 & 0 & $1(1)$ & $0(0)$ & 0 \\
\hline \multirow[t]{8}{*}{ Micromonosporaceae } & Micromonospora & 10 & 17 & $8(8)$ & $11(11)$ & 0 \\
\hline & Actinoplanes & 21 & 13 & $15(14)$ & $9(8)$ & 1 \\
\hline & Catellatospora & 0 & 3 & $0(0)$ & $2(2)$ & 0 \\
\hline & Couchioplanes & 0 & 1 & $0(0)$ & $1(1)$ & 0 \\
\hline & Dactylosporangium & 1 & 15 & $1(1)$ & $10(10)$ & 0 \\
\hline & Pilimelia & 0 & 1 & $0(0)$ & $1(1)$ & 0 \\
\hline & Verrucosispora & 0 & 13 & $0(0)$ & $2(2)$ & 0 \\
\hline & Virgisporangium & 1 & 0 & $1(1)$ & $0(0)$ & 0 \\
\hline Nocardioidaceae & Hongia & 20 & 3 & $6(4)$ & $2(0)$ & 2 \\
\hline \multirow[t]{2}{*}{ Pseudonocardiaceae } & Amycolatopsis & 33 & 5 & $11(10)$ & $3(2)$ & 1 \\
\hline & Kibdelosporangium & 0 & 1 & $0(0)$ & $1(1)$ & 0 \\
\hline Actinosynnemataceae & Saccharothrix & 1 & 0 & $1(1)$ & $0(0)$ & 0 \\
\hline \multirow[t]{2}{*}{ Streptomycetaceae } & Streptomyces & 672 & 541 & $101(71)$ & $90(60)$ & 30 \\
\hline & Kitasatospora & 10 & 1 & $5(5)$ & $1(1)$ & 0 \\
\hline \multirow[t]{7}{*}{ Streptosporangiaceae } & Streptosporangium & 136 & 20 & $18(16)$ & $9(7)$ & 2 \\
\hline & Acrocarpospora & 3 & 0 & $2(2)$ & $0(0)$ & 0 \\
\hline & Herbidospora & 2 & 0 & $2(2)$ & $0(0)$ & 0 \\
\hline & Microbispora & 1 & 14 & $1(1)$ & $3(3)$ & 0 \\
\hline & Microtetraspora & 1 & 22 & $1(0)$ & $2(1)$ & 1 \\
\hline & Nonomuraea & 4 & 69 & $3(0)$ & $14(11)$ & 3 \\
\hline & Planotetraspora & 31 & 8 & $5(3)$ & $3(1)$ & 2 \\
\hline Thermomonosporaceae & Actinomadura & 6 & 11 & $5(4)$ & $5(4)$ & 1 \\
\hline$?$ & Cryptosporangium & 1 & 0 & $1(1)$ & $0(0)$ & 0 \\
\hline$?$ & Kutzneria & 1 & 0 & $1(1)$ & $0(0)$ & 0 \\
\hline$?$ & undescribed genus & 0 & 2 & $0(0)$ & $1(1)$ & 0 \\
\hline \multicolumn{2}{|c|}{ Total } & 981 & 790 & $207(159)$ & $185(137)$ & 48 \\
\hline
\end{tabular}

roseola. However, on the phylogenetic tree, 413B06 is located outside the Nonomuraea clade. The taxonomic position of 413B06 is unclear. Recently, Nakajima et al. described "Microtetraspora malaysiensis" sp. nov. for Malaysian soil isolates ${ }^{30)}$. We isolated 22 Microtetraspora strains from Malaysia, with 14 demonstrating homology value of 99-100\% with "Microtetraspora malaysiensis" (Fig. 6). From Japan, only one strain (343A05) was isolated; its homology value with respect to Microtetraspora glauca was $99.3 \%$.

Among Micromonosporaceae, the predominant genus in Japanese isolates was Actinoplanes (60\%). This figure was lower $(25 \%)$ in Malaysian isolates. Dactylosporangium $(27 \%)$ was higher in Malaysian isolates.

In this study, most of the isolates that were simple-identified as Actinomadura species formed a cluster around $A$. spadix (Fig. 7). Zhang et al. have argued that A. spadix should not be included in Actinomadura ${ }^{31)}$. This clustering also agreed with the cluster proposed by Wang, "Potential novel genus in Thermomonosporaceae"4).

\section{Taxonomical position of candidate strains of novel} genus

Isolates 413C04 and 413C05 offered no species with high homology values. The species with the highest homology value was Actinomadura livida $\mathrm{JCM} 3387^{\mathrm{T}}$, which exhibited a value of 92\% (415/449 nucleotides). These isolates are closely related to Thermobifida, Streptomonospora, and Nocardiopsis, but do not form a cluster with any of them (Fig. 8). The phylogenetic tree indicates they belong to an undescribed genus that belongs or is closely related to the family Nocardiopsaceae. These strains were isolated from the same soil sample, same isolation method (air-drying), and same isolation plate (HV agar with erythromycin). The strains produce white aerial hyphae and spore chains and have identical morphological characteristics. Except for differences considered to be errors in sequence determination (single " $n$ " insertion and " $t$ " addition at the end of sequence), their sequences were identical. They may be clones. Further investigations of phylogenetic, chemotax- 
A
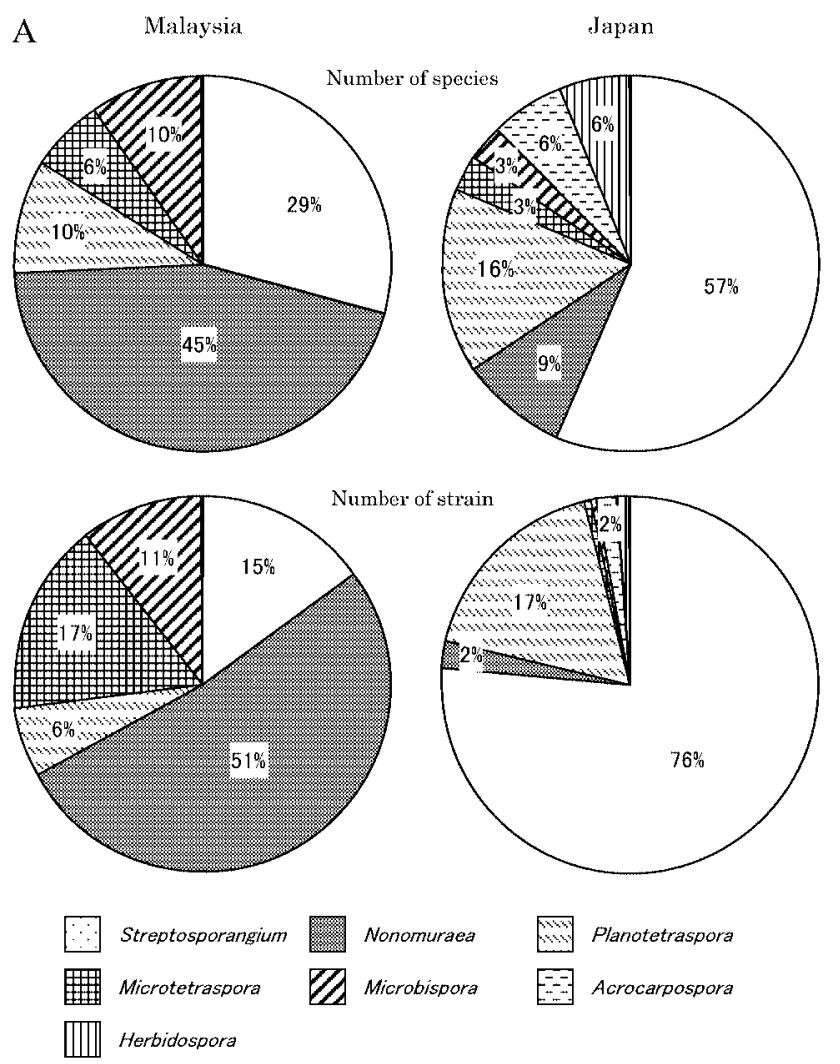
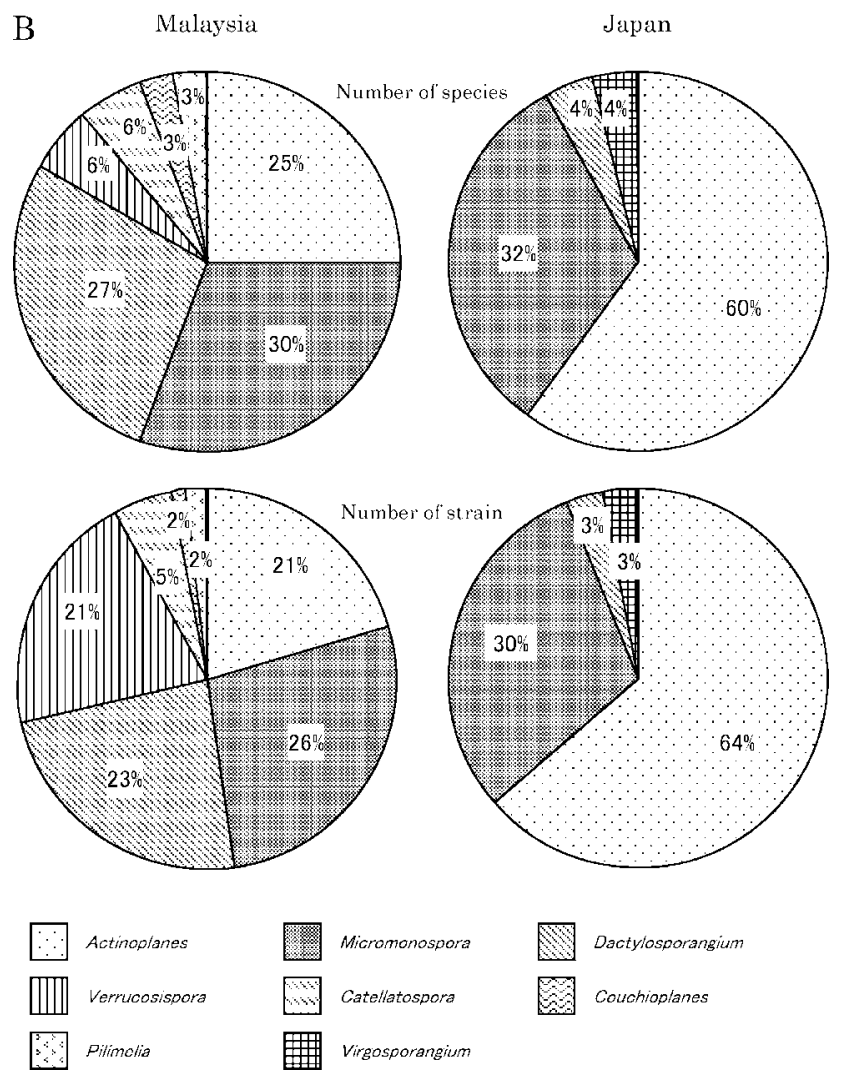

Fig. 3. Frequencies of genera on families.

A: Streptosporangiaceae; B: Micromunosporaceae

The percentages on the graphs are the frequencies of genera (above $2 \%$ are indicated).

onomic, and morphological properties are required to confirm their taxonomical position.

\section{Malaysian actinomycetes as a source for screening for novel bioactive compounds}

This study found no significant difference in the numbers of actinomycete species between soil samples from Malaysia and Japan. These results are inconsistent with the differences observed between the two regions in plants and other higher organisms. But the study also found relatively little overlap between species isolated from Japan and Malaysia. Hence, a collection of actinomycetes obtained from both regions will naturally have greater taxonomic diversity than from only one. Two of the Malaysian isolates examined do not belong to any known genus, suggesting that Malaysian actinomycetes have yet to be fully investigated. Malaysian actinomycetes represent a promising source for the discovery of novel bioactive compounds.

\section{ACKNOWLEDGEMENT}

We thank Mayumi Amako, Yosie Aishima, and Keiko Takeda for technical assistance.

\section{REFERENCES}

1) Watve, M. G.; R. Tickoo \& M. M. Jog: How many antibiotics are produced by the genus Streptomyces? Arch. Microbiol. 176: 386-390, 2001

2) Bull, A. T.; M. Goodfellow \& J. H. Slater: Biodiversity as a source of innovation in biotechnology. Annu. Rev. Microbiol. 46: 219-252, 1992

3) Myers, N.: Threatened biotas: 'hot spots' in tropical forests. Environmentalist 8: 1-20, 1988

4) Wang, Y.; J. S. Zhang, J. S. Ruan, Y. M. Wang \& S. M. Ali: Investigation of actinomycete diversity in the tropical rainforests of Singapore. J. Ind. Microbiol. Biotechnol. 23: 178-187, 1999

5) Xu, L. H.; Q. R. Li \& C. Jiang: Diversity of soil actinomycetes in Yunnan, China. Appl. Environ. Microbiol. 62: 244-248, 1996

6) Balagurunathan, R.; L. Xu \& C. Jiang: Diversity of soil actinomycetes from south India and south China. Actinomycetes 7: 89-94, 1996

7) Wang, Y. M.; Z. S. Zhang, X. L. Xu, J. S. Ruan \& Y. Wang: Actinopolymorpha singaporensis gen. nov., sp. nov., a novel actinomycete from the tropical rainforest of Singapore. Int. J. Syst. Evol. Microbiol. 51: 467-473, 2001

8) Tsuchizaki, N.; M. Hamada \& K. Hotta: Rapid characterization by colony direct PCR of distribution specificity in Streptomyces of kan gene encoding a specific aminoglycoside-3- $N$-acetyltransferase. Actinomycetol. 15: 23-29, 2001 


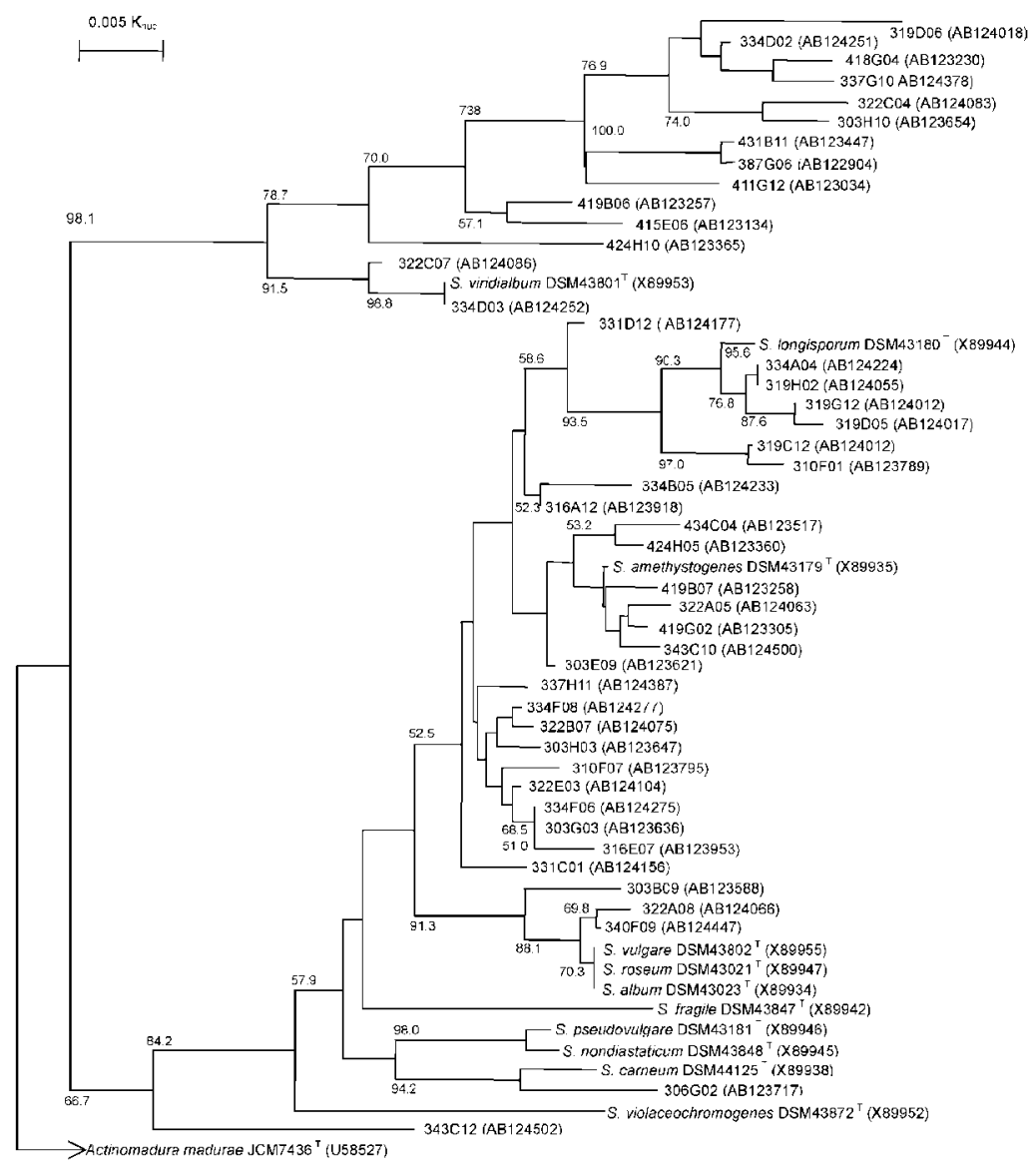

Fig. 4. The phylogenetic tree of members belong to the genus Streptosporangium based on partial sequence of 16S rDNA (c.a. 560 nucleotides, nucleotide position: 89-653 according to the Streptomyces ambofaciens rDNA sequence).

The numbers on the branches are confidence limits (expressed as percentages) estimated from a bootstrap analysis with 1000 replicates (above $50 \%$ are indicated).

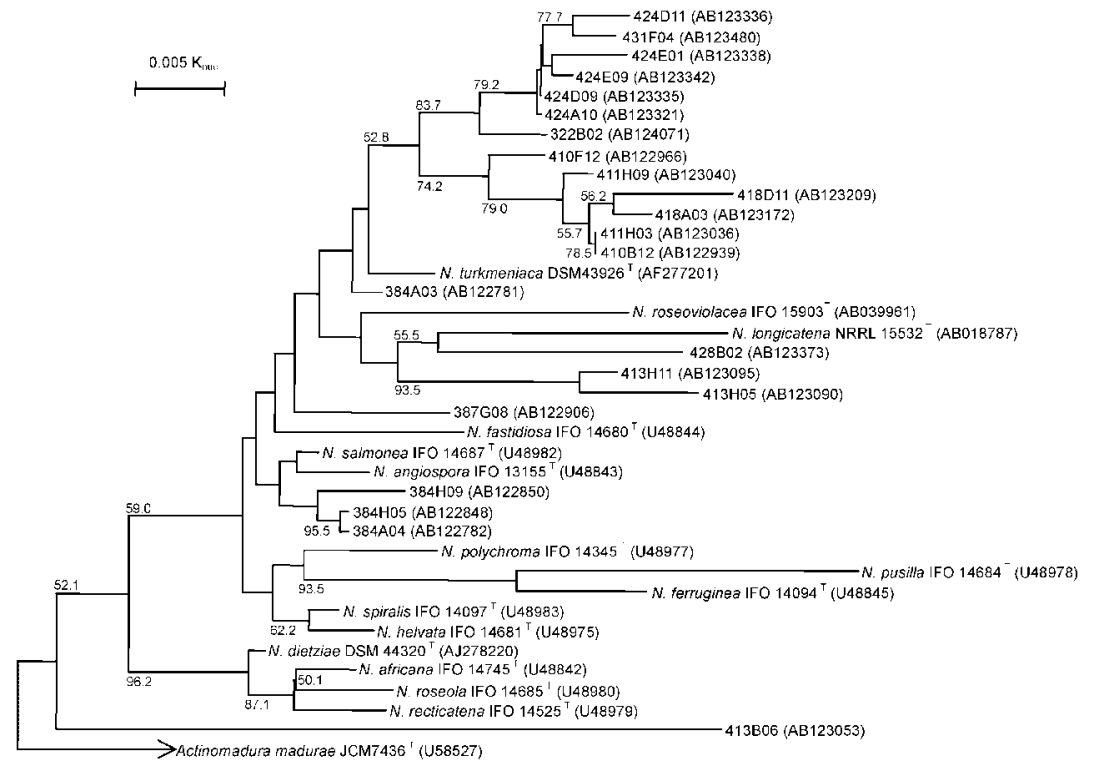

Fig. 5. The phylogenetic tree of members belong to the genus Nonomuraea based on partial sequence of 16S rDNA (c.a. 560 nucleotides, nucleotide position: 89-653 according to the Streptomyces ambofaciens rDNA sequence).

The numbers on the branches are confidence limits (expressed as percentages) estimated from a bootstrap analysis with 1000 replicates (above 50\% are indicated). 


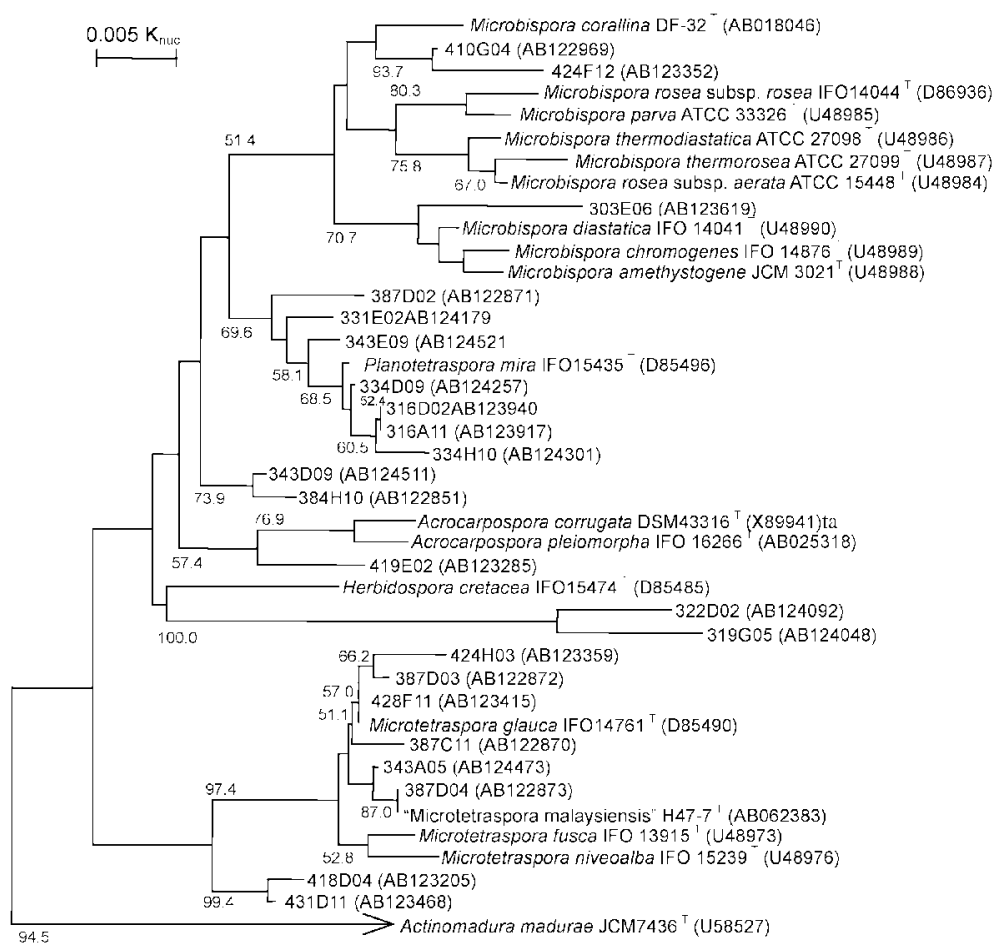

Fig. 6. The phylogenetic tree of members belong to the genera Microbispora, Microtetraspora, Acrocarpospora, Herbidospora, and Planotetraspora based on partial sequence of 16S rDNA (c.a. 560 nucleotides, nucleotide position: 89-653 according to the Streptomyces ambofaciens rDNA sequence).

The numbers on the branches are confidence limits (expressed as percentages) estimated from a bootstrap analysis with 1000 replicates (above 50\% are indicated).

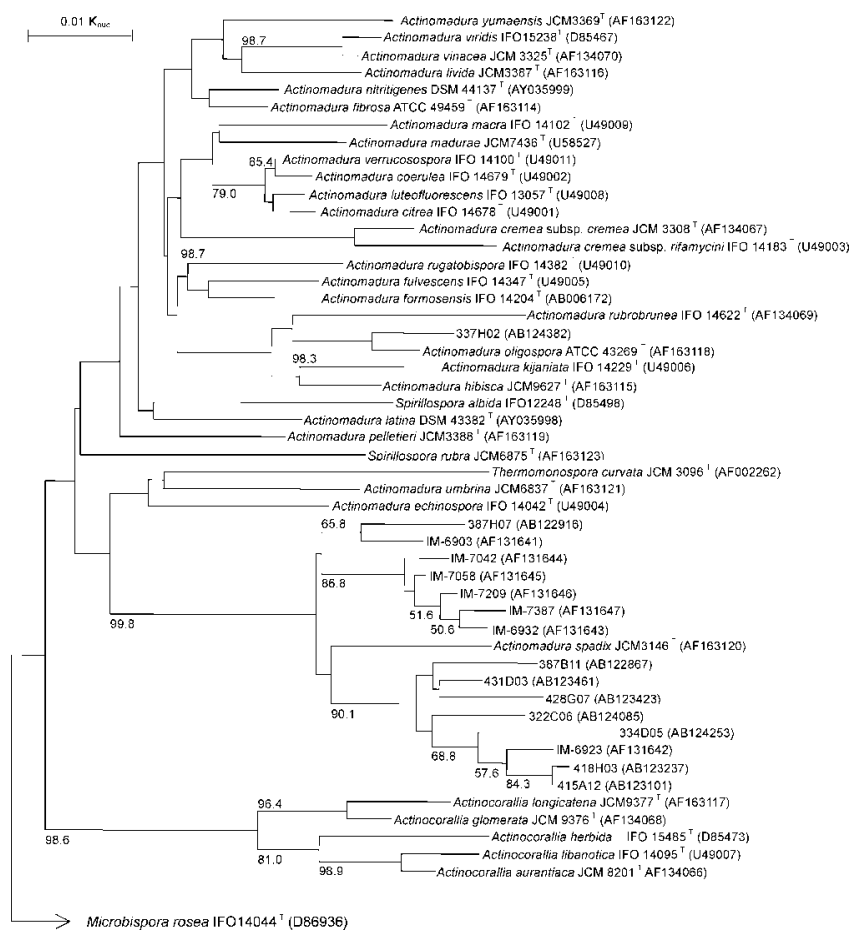

Fig. 7. The phylogenetic tree of members belong to the family Thermomonosporaceae based on partial sequence of 16S rDNA (c.a. 560 nucleotides, nucleotide position: 89-652 according to the Streptomyces ambofaciens rDNA sequence).

The numbers on the branches are confidence limits (expressed as percentages) estimated from a bootstrap analysis with 1000 replicates (above 50\% are indicated). 


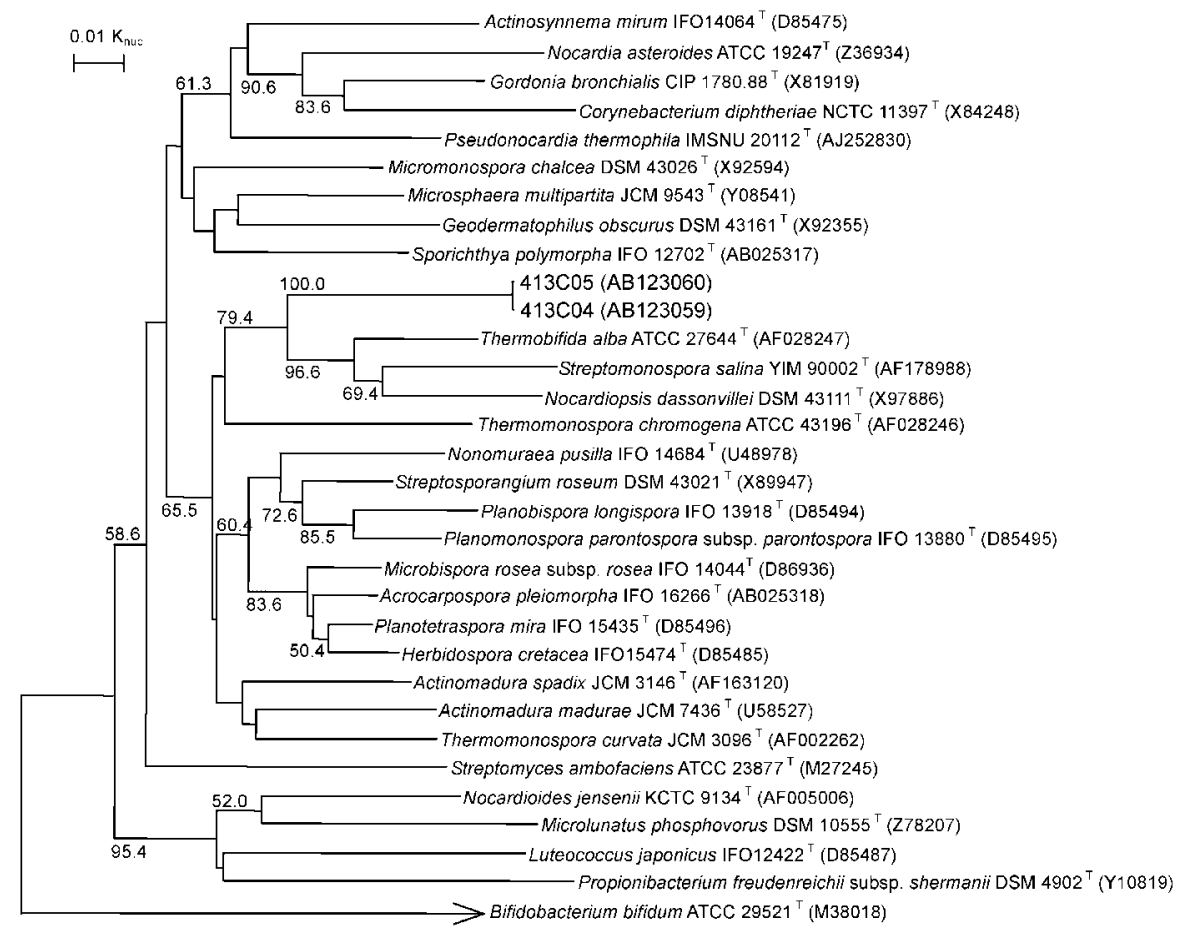

Fig. 8. Phylogenetic tree showing the position of strains $413 \mathrm{C} 04$ and $413 \mathrm{C} 05$ based on partial sequence of 16S rDNA (c.a. 560 nucleotides, nucletide position: 89-653 according to the Streptomyces ambofaciens rDNA sequence).

The numbers on the branches are confidence limits (expressed as percentages) estimated from a bootstrap analysis with 1000 replicates (above $50 \%$ are indicated).

9) Hai, L. E. \& A. Z. Yahya: A note on the growth performance of plantation grown Aquilaria malaccensis in Peninsular Malaysia. Journal of Tropical Forest Science 8: 573-575, 1996

10) Japanese Meteorogical Agency: http://www.data.kishou.go.jp/ (Japanese).

11) Takeuchi, S.; M. Hayakawa \& T. Yamazaki: A simplified approach to the selective isolation of motile actinomycetes. In Abstract of The 1996 Annual Meeting of The Society for Actinomycetes Japan. The Society for Actinomycetes Japan, Tokyo, Japan. (Japanese). Abstr. 2. p. 2.

12) Hayakawa, M.; H. Iino, S. Takeuchi \& T. Yamazaki: Application of a method incorporating treatment with Chloramine-T for the selective isolation of Streptosporangiaceae from soil. J. Ferment. Bioeng. 84: 599-602, 1997

13) Hayakawa, M. \& H. Nonomura: Humic acid-vitamin agar, a new medium for selective isolation of soil actinomycetes. J. Ferment. Technol. 65: 501-509, 1987

14) Pernodet, L. L.; F. Boccard, M. T. Alegre, J. Gagnat \& M. Guérineau: Organization and nucleotide sequence analysis of a ribosomal RNA gene cluster from Streptomyces ambofaciens. Gene 79: 33-46, 1989

15) DNA Data Bank of Japan: http://www.ddbj.nig.ac.jp/

16) Wang, Y.; Z. Zhang \& J. Ruan: Phylogenetic analysis reveals new relationships among members of the genera Microtetraspora and Microbispora. Int. J. Syst. Bacteriol. 46: 658-663, 1996

17) Koch, C.; R. M. Kroppenstedt \& E. Stackebrandt: Intrageneric relationships of the actinomycete genus Micromonospora. Int. J. Syst. Bacteriol. 46: 383-387, 1996
18) Wang, Y.; Z. Zhang \& J. Ruan: A proposal to transfer Microbispora bispora (Lechevalier 1965) to a new genus, Thermobispora gen. nov., as Thermobispora bispora comb. nov. Int. J. Syst. Bacteriol. 46: 933-938, 1996

19) Yassin, A. F.; F. A. Rainey, J. Burghardt, D. Gierth, J. Ungerechts, I. Lux, P. Seifert, C. Bal \& K. P. Schaal: Description of Nocardiopsis synnmataformans sp. nov., elevation of Nocardiopsis alba subsp. prasina to Nocardiopsis prasina comb. nov., and Designation of Nocardiopsis antarctica and Nocardiopsis alborubida as later subjective synonyms of Nocardiopsis dassonvillei. Int. J. Syst. Bacteriol. 47: 983-988, 1997

20) Zhang, Z.; Y. Wang \& J. Ruan: A proposal to revive the genus Kitasatospora (Omura, Takahashi, Iwai, and Tanaka 1982). Int. J. Syst. Bacteriol. 47: 1048-1054, 1997

21) Goodfellow, M.; A. B. Brown, J. Cai, J. Chun \& M. D. Collins: Amycolatopsis japonicum sp. nov., an actinomycete producing (S,S)-N, N'-ethylenediaminedisuccinic acid. System. Appl. Microbiol. 20: 78-84, 1997

22) Zhou, Z. H.; Z. H. Liu, Y. D. Qian, S. B. Kim \& M. Goodfellow: Saccharopolyspora spinosporotrichia sp. nov., a novel actinomycete from soil. Int. J. Syst. Bacteriol. 48: 53-58, 1998

23) Zhang, Z.; Y. Wang \& J. Ruan: Reclassification of Thermomonospora and Microtetraspora. Int. J. Syst. Bacteriol. 48: 411-422, 1998

24) Lee D. S.; E. S. Kim, Y. C. Hah: Phylogenetic analysis of the genera Pseudonocardia and Actinobispora based on 16S ribosomal DNA sequences. FEMS Microbiol. Lett. 182: 125-129, 2000

25) Keswani, J. \& W. B. Whitman: Relationship of $16 \mathrm{~S}$ rRNA 
sequence similarity to DNA hybridization in prokaryotes. Int. J. Syst. Evol. Microbiol. 51: 667-678, 2001

26) Saitou, N. \& M. Nei: The neighbor joining method: a new method of constructing phylogenetic trees. Mol. Biol. Evol. 6: 514-525, 1987

27) Thompson, J. D.; T. J. Gibson, F. Plewniak, F. Jeanmougin \& D. G. Higgins: The Clustal X windows interface: flexible strategies for multiple sequence alignment aided by quality analysis tools. Nucleic Acids Research 24: 4876-4882, 1997

28) Hayakawa, M.; K. Ishizawa \& N. Nonomura: Distribution of rare actinomycetes in Japanese soils. J. Ferment. Technol. 66: 367-373, 1988.

29) Tamura, T.; S. Suzuki \& K. Hatano: Acrocarpospora gen. nov., a new genus of the order Actinomycetales. Int. J. Syst. Evol. Microbiol. 50: 1163-1171, 2000

30) Nakajima, Y.; C. C. Ho \& T. Kudo: Microtetraspora malaysiensis sp. nov., isolated from Malaysian primary dipterocarp forest soil. J. Gen. Appl. Microbiol. 49: 181-189, 2003

31) Zhang, Z.; T. Kudo, Y. Nakajima \& Y. Wang: Clarification of relationship between the members of the family Thermomonosporaceae on the basis of 16S rDNA, 16S-23S rRNA internal transcribed spacer and $23 \mathrm{~S}$ rDNA sequences and chemotaxonomic analyses. Int. J. Syst. Evol. Microbiol. 51: 373-383, 2001 